\title{
België
}

\section{Belgisch erfrecht grondig herzien}

Prof. mr. W.D. Kolkman*

\section{Inleiding}

Op 25 januari 2017 zag in België een wetsvoorstel het licht tot fundamentele aanpassing van het erfrecht. ${ }^{1}$ Met ongekende snelheid is dit voorstel door het parlement geloodst, leidend tot de Wet van 31 juli 2017. ${ }^{2}$ De 'Erfwet 2017' treedt op 1 september 2018 in werking.

Op drie onderdelen introduceert de wet wezenlijke wijzigingen: de erfrechtelijke reserve, de inbreng van giften en de erfovereenkomsten. ${ }^{3}$ Op elk van deze onderdelen ga ik hierna in (par. $3 \mathrm{t} / \mathrm{m} \mathrm{5}$ ), waarbij ik een vergelijking maak met de Nederlandse situatie. Het zal blijken dat België enkele stappen zet die ook in het Nederlandse erfrecht niet zouden misstaan.

De Belgische modernisering past in een Europese trend. Het Nederlandse erfrecht veranderde op 1 januari 2003 van koers. Frankrijk voerde verregaande aanpassingen door in 2002 en 2007, Duitsland in 2010 (in bescheidener omvang), Hongarije in 2014 en Oostenrijk per 1 januari $2017 .{ }^{4}$ Opvallend is dat deze laatste wetgevingsoperatie ook vliegensvlug plaatsvond, met slechts

* Prof. mr. W.D. Kolkman is hoogleraar Algemene Rechtswetenschap en Familievermogensrecht aan de Rijksuniversiteit Groningen en adviseur bij Elan Notarissen.

1. Voluit: het Wetsvoorstel tot wijziging van het Burgerlijk Wetboek wat de erfenissen en de giften betreft en tot wijziging van diverse andere bepalingen ter zake.

2. Zie in breder perspectief: D. Heirbaut \& M. van der Haegen, De sprong van Geens: het grootste codificatieplan uit de Belgische geschiedenis in context, Rechtskundig Weekblad 2017-18, nr. 36, p. 1403 e.v.

3. Andere wijzigingen, zoals die ten aanzien van de verdeling, zijn van ondergeschikt belang. Ik laat deze hier onbesproken. Zie voor een overzicht B.C.M. Waaijer, De Belgische erfrechthervorming: ook van de legitieme portie!, WPNR 2017/7155.

4. Zie de bijdrage van Ferrari en Köllich in dit themanummer. één jaar parlementaire behandeling. De reden hiervoor was dat Oostenrijk wilde ansluiten bij de EU-Erfrechtverordening. ${ }^{5}$

Ik voeg enkele leeswijzers bij. Deze bijdrage gaat uit van de wettekst zoals die in België van toepassing is sinds 1 september 2018; met de term 'oud erfrecht' doel ik derhalve op de situatie vóór genoemde datum. Voor Nederland geldt mutatis mutandis hetzelfde, met als omslagpunt 1 januari 2003.

Om spraakverwarring te voorkomen, gebruik ik zo veel mogelijk de in het land van herkomst gebezigde terminologie. Zo gaat paragraaf 3 over de Belgische erfrechtelijke reserve. Veelal wordt dit naar het Nederlands vertaald met legitieme portie. Dat lijkt mij echter te beperkt. De Nederlandse nalatenschap is ook 'gereserveerd' voor de andere mettelijke rechten, toekomend aan de langstlevende echtgenoot en de kinderen van de erflater. $\mathrm{Bij}$ vergelijking tussen beide systemen beschouw ik daarom de Nederlandse 'legitieme portie en andere wettelijke rechten' als tegenhanger van de Belgische 'reserve'. Ook bij de term gift ligt Babylonië op de loer. Het Belgische recht verstaat onder gift zowel de schenkingen bij leven als testamentaire bevoordelingen in de vorm van een legaat. Het Nederlandse begrip is beperkter: slechts bevoordelingen onder de levenden vallen eronder. Waar ik hieronder van gift spreek, bedoel ik schenkingen en legaten (de Belgische betekenis derhalve). Bevoordelingen tijdens leven zal ik aanduiden met de term schenking.

5. C. Rabl, Das Erbrechtsänderungsgesetz 2015, in: C. Rabl \& B. ZöchlingJud (red.), Das neue Erbrecht, Wenen: Manz Verlag 2015, p. 4 e.v. De verordening schrijft echter geen materiële wijzigingen voor. 


\section{Redenen voor herziening}

De moderniseringen in de verschillende landen laten zich verklaren door de ouderdom van de tot kort geleden vigerende stelsels. Zo stamt het Nederlandse oude erfrecht uit 1838. Ook in België wil men nu Napoleon van zich afschudden. De toelichting noemt als belangrijkste drijfveer voor de Belgische hervorming dat de huidige regels grotendeels steunen op het maatschappijmodel ten tijde van de invoering van het Burgerlijk Wetboek (BW), dat sinds die napoleontische tijd echter sterk is geëvolueerd. ${ }^{6}$

Het klassieke gezin van gehuwde ouders met kinderen wordt steeds minder de norm. De complexiteit van de maatschappelijke realiteit noopt tot een flexibilisering van het erfrecht, die toelaat om in te spelen op de veelheid aan familievormen. ${ }^{7}$ De toelichting voert voorts aan dat de focus ligt op het 'kerngezin' (echtgenoot en kinderen); familiebanden met verdere verwanten hebben aan belang ingeboet. Daarnaast zorgt de hogere levensverwachting ervoor dat men doorgaans pas erft in een latere fase van het leven. Tot slot vormt de 'onnodige complexiteit' van de huidige regeling een grond voor aanpassing. ${ }^{8}$

\section{Erfrechtelijke reserve}

\subsection{Algemeen}

In mijn ogen is de meest ingrijpende wijziging die van de aard en omvang van de reservataire aanspraken. Ten dele bewandelt België hier dezelfde route als Nederland in 2003. De 'goederenrechtelijke' reserve voor de kinderen verdwijnt naar de geschiedenisboeken en maakt plaats voor een op Duitse leest geschoeide geldvordering. Met andere woorden: het dwingende erfrecht verschuift - althans grotendeels - van in natura naar in waarde.

Het oude Belgische reservataire erfrecht vertoonde veel gelijkenissen met het Nederlandse dwingende erfrecht van voor 2003, of - preciezer - van voor 1996, met een goederenrechtelijke reserve voor zowel de afstammelingen als de bloedverwanten in opgaande lijn. Deze werd in natura verkregen, de breuk was afhankelijk van het antal kinderen van de erflater; de berekening van de massa verliep langs dezelfde lijnen. Een wezenlijk verschil was de groep van gerechtigden: sinds 1996 zijn in Nederland slechts de afstammelingen van de erflater legitimaris, terwijl in België ook aan de echtgenoot en aan de ascendenten een aanspraak toekomt. In Nederland werden in 1996 de ascendenten geschrapt, in Frankrijk gebeurde dat in 2007. Daar moet echter rekening worden gehouden met het 'droit de retour' van

\footnotetext{
Zie MvT, Parl. St. Kamer, 54 2281/001, p. 5.

Zie noot 6 .

Zie noot 6 .
}

artikel 738 lid $2 \mathrm{Cc}$, dat in voorkomende gevallen een legitimaire functie kan vervullen. ${ }^{9}$

In Nederland ontbrak tot 2003 de langstlevende echtgenoot nagenoeg geheel in het versterferfrecht. Het nieuwe erfrecht maakte dat ruimschoots goed: naast een vooraanstaande positie ab intestato kreeg de echtgenoot een dwingende verzorgingsaanspraak. Onder de noemer 'andere wettelijke rechten' kan de langstlevende, voor zover behoeftig, een vruchtgebruik verkrijgen op woning, inboedel en overige goederen van de nalatenschap (zie par. 3.3).

De gerechtigden tot de dwingende erfrechtelijke aanspraken vallen in België uiteen in drie groepen. Ten eerste zijn er de afstammelingen van de erflater (art. 913 BelgBW). Zij hebben recht op een geldvordering. Ten tweede de echtgenoot (art. 915bis BelgBW), met een recht op vruchtgebruik. Ten derde de bloedverwanten in opgaande lijn (art. 205bis BelgBW), aan wie de wet een onderhoudsaanspraak toekent. Ik bespreek deze drie groepen achtereenvolgens.

\subsection{Reserve: afstammelingen}

De degradatie van de reserve per 1 september 2018 komt het sterkst naar voren in de nieuwe aard van de anspraak: de afstammeling heeft niet langer recht op een gedeelte van de massa, maar op een gedeelte van de maarde van de massa. ${ }^{10}$ Daar komt nog bij dat het breukdeel ook is geërodeerd. Het oude artikel 913 BelgBW kende evenals het Nederlandse artikel 961 OBW (tot 2003) de napoleontische trits: het beschikbare deel is de helft bij een kind, een derde bij twee kinderen, een kwart bij drie of meer kinderen. Thans beloopt het breukdeel de helft, ongeacht de omvang van de kinderschare.

De toename van het beschikbare deel (dat in België als gezegd niet alleen wordt beïnvloed door de anwezigheid van kinderen) impliceert een grotere vrijheid voor de schenker en testateur. De helft is heden ten dage de veelvoorkomende breuk voor het beschikbare deel, zie bijvoorbeeld, naast België en Nederland, ook Duitsland ${ }^{11}$ en Oostenrijk. ${ }^{12}$

De traditionelere stelsels kennen vooralsnog een kleiner beschikbaar deel. Zo bijvoorbeeld Italië, met zijn goederenrechtelijke legittima oplopend tot $3 / 4 .{ }^{13}$ Zuid-Amerika kent nog grotere inbreuken op de testeervrijheid: in Paraguay is het legitimaire breukdeel 4/5, in Argentinië was dit tot 2015 ook het geval (inmiddels gereduceerd

9. D. Arteil, L'ascendant dans le nouveau droit des libéralités et des successions, Répertoire du notariat Defrénois 2007, p. 477-508. Vergelijk in Nederland de herroepelijke schenking.

10. In art. 920 BelgBW bevinden zich enkele uitzonderingen, op basis waarvan toch een reserve in natura kan worden verkregen.

11. § $2303 \mathrm{BGB}$.

12. § $759 \mathrm{ABGB}$.

13. A. Braun, Testamentary freedom and its restrictions in French and Italian law: Trends and shifts, in: R. Zimmermann (red.), Freedom of testation/Testierfreiheit, Tübingen: Mohr Siebeck 2012, p. 62 e.v. Zie ook de bijdrage van Christandl en Dallago in dit themanummer. 
tot 2/3). ${ }^{14}$ Minder kan ook: in Hongarije beloopt de legitieme $1 / 3.15$

Van oudsher verkrijgt de reservatair gerechtigde een aanspraak op een massa die bestaat uit het relictum plus het donatum. De Belgische berekenwijze is sinds 1 september 2018 versimpeld, maar echt eenvoudig zullen reservataire sommen nooit worden. De waardering van schenkingen is bij de regeling van de reserve op één lijn gebracht met die van de inbreng. In Nederland gebeurde dit net andersom, maar met hetzelfde resultaat: sinds 2003 grijpen de inbrengregels terug op die van de legitieme portie.

Voor de maardering van schenkingen geldt thans de intrinsieke waarde van het geschonken goed op de dag van de schenking, met indexering (art. 858 \& 3 lid 1 BelgBW). Drie opmerkingen hierover.

Ten eerste het tijdstip van de waardering. Dat komt overeen met artikel 4:66 lid 1 NedBW: het moment van de prestatie. Ook de uitzonderingen daarop, bijvoorbeeld als een genotsrecht wordt voorbehouden, vertonen grote gelijkenissen (art. 4:66 lid 2 en 3 NedBW, art. 858 $\S 3 \operatorname{lid} 2$ BelgBW).

Ten tweede de indexering. Hier divergeren de beide systemen. Het Belgische recht indexeert de waarde van de schenking vanaf de dag van de schenking tot op de dag van het overlijden, overeenkomstig de index van de consumptieprijzen van de maand van het overlijden van de schenker, met als basisindex die van de maand waarin de schenking werd gedaan (art. 858 § 3 lid 2 BelgBW). Dit lijkt mij voor het Nederlandse recht een zinvolle verbetering. Zeker bij oude schenkingen kan de waardering zonder indexering nadelig uitpakken voor de legitimaris. Met vruchten van het geschonkene wordt noch in Nederland, noch in België rekening gehouden.

Ten derde de intrinsieke waarde. Deze term brengt tot uitdrukking dat rekening wordt gehouden met de inherente kwaliteiten van het goed op de dag van de schenking, zelfs indien partijen bij de schenking deze niet kenden. ${ }^{16}$ Als voorbeeld geeft de toelichting de schenking van een schilderij waarvan partijen, op het ogenblik van de schenking, onwetend waren dat het een meesterwerk met aanzienlijke waarde betreft. De waardering zal plaatsvinden rekening houdende met het feit dat het om een meesterwerk gaat. Hetzelfde geldt in het geval de schenking een perceel grond betreft waarvan de partijen op het ogenblik van de schenking niet wisten dat dit vervuild was: de waardering geschiedt in vervuilde staat. ${ }^{17}$ Hoewel het Nederlandse BW niet een dergelijke specificatie bevat bij de waardering, neem ik aan dat het systeem niet van het Belgische verschilt. Zowel het onbekende meesterwerk als de vervuilde grond zal voor die werkelijke waarde (in het economisch verkeer) meespelen in de legitimaire massa.

\footnotetext{
14. Art. 2445 Código Civil y Comercial de la República Argentina 2015

15. Art. 7:82 lid 1 BW Hongarije 2013.

16. MvT, Parl. St. Kamer, $542281 / 001$, p. 63

17. Ibidem.
}

\subsection{Reserve: echtgenoot}

In België komt aan de echtgenoot ${ }^{18}$ van de erflater een tweevoudige reserve toe: de abstracte en de concrete reserve. De abstracte reserve volgt uit artikel 915bis $\S 1$ BelgBW: niettegenstaande elke andersluidende bepaling verkrijgt de langstlevende echtgenoot het vruchtgebruik van de helft van de reservataire massa. De concrete reserve garandeert de echtgenoot het vruchtgebruik of de huur van de woning en inboedel (art. 915bis $\S 2$ BelgBW). Kiest de echtgenoot de concrete reserve en is deze minder waard dan de abstracte, dan kan zij worden aangevuld tot de grens van de laatste.

Ter compensatie van de beperking van de reserve van de afstammelingen tot de helft volgt nu uit artikel 914 BelgBW dat kinderen hun erfdeel zo veel mogelijk onbezwaard met vruchtgebruik van de langstlevende echtgenoot ontvangen. Zo herdefinieert de nieuwe wet het evenwicht tussen de langstlevende en de kinderen. ${ }^{19}$

In Nederland heeft de dwingende claim van de echtgenoot eveneens de vorm van een vruchtgebruik: op de woning en inboedel (art. 4:29 NedBW), en op de overige goederen van de nalatenschap (art. 4:30 NedBW). Het eerstgenoemde vruchtgebruik lijkt op de 'concrete reserve', het tweede op de 'abstracte'. Toch bestaan er wezenlijke verschillen.

Het cruciale element voor zowel artikel 4:29 als artikel 4:30 NedBW is de verzorgingsbehoefte: deze rechten vormen niet meer dan een vangnet voor de langstlevende, resulterende in het bereiken van een 'passend verzorgingsniveau', dat te vergelijken is met alimentatie. Volgens de Hoge Raad ligt de bewijslast bij artikel 4:29 NedBW bij de erfgenamen (zij dienen aan te tonen dat de echtgenoot van de erflater geen behoefte heeft aan het vruchtgebruik op de woning en inboedel), bij het vruchtgebruik op de andere goederen is het precies andersom. ${ }^{20}$ Een beroep op de Nederlandse 'concrete reserve' heeft om deze reden meer kans van slagen dan een beroep op de 'abstracte reserve'.

Een ander verschil schuilt in het plafond dat de Belgische wet aan de abstracte reserve koppelt: slechts de helft van de massa kan met het vruchtgebruik worden belast. In Nederland valt de gehele massa daaraan ten prooi, mits van behoeftigheid sprake is.

Een overeenkomst tussen beide stelsels is dat zij een beroep op het vruchtgebruik willen voorkomen wanneer het tussen de echtgenoten al geruime tijd niet meer botert. In Nederland gaat dat van rechtswege: artikel 4:32 NedBW komt erop neer dat geen vruchtgebruik kan worden geclaimd wanneer de echtgenoot en de erflater al langer dan een jaar in echtscheiding lagen. ${ }^{21}$ In

18. Sinds 18 mei 2007 speelt naast de echtgenoot ook de 'wettelijk samenwonende' een rol in het Belgische erfrecht, en wel hoofdzakelijk in het versterferfrecht, dat de samenwoner een vruchtgebruik op woning en inboedel toekent (art. 745octies BelgBW).

19. MvT, Parl. St. Kamer, $542281 / 001$, p. 4.

20. HR 8 juni 2007, NJ 2008/220.

21. Bijzonder is dat de blokkade niet werkt 'indien de omstandigheid dat de echtscheiding niet meer tot stand heeft kunnen komen niet in overwegende mate aan de langstlevende echtgenoot kan worden toegerekend' 
België is een testamentaire voorziening vereist, maar de termijn is korter. De reservataire rechten kunnen bij uiterste wil aan de langstlevende worden ontnomen, indien de echtgenoten op de dag van het overlijden sinds meer dan zes maanden gescheiden leefden en, kort gezegd, een echtscheidingsprocedure aanhangig was (art. 915bis $\S 3$ BelgBW).

\subsection{Onderhoudsaanspraak: ascendenten}

Het oude Belgische recht rekende de bloedverwanten in opgaande lijn tot de reservataire erfgenamen (art. 915 BelgBW oud). Het nieuwe recht vervangt de ascendentenreserve door een onderhoudsaanspraak jegens de nalatenschap: 'De nalatenschap van degene die overleden is zonder nakomelingen achter te laten is levensonderhoud verschuldigd aan de bloedverwanten in opgaande lijn van de erflater die ten tijde van het overlijden of door het overlijden behoeftig zijn' (art. 205bis $\S 2$ BelgBW). Het maximum voor deze alimentaire voorziening per opgaande lijn van bloedverwanten bedraagt een kwart van de reservataire massa, hetgeen overigens overeenkomt met het breukdeel van hun oude reserve.

Een interessante overgang van forfaitaire reserve naar op maat gesneden onderhoudsaanspraak. Ik trek twee parallellen. Ten eerste vestig ik de aandacht op het Nederlandse artikel 4:35 NedBW, dat aan minderjarige kinderen een onderhoudsaanspraak jegens de gezamenlijke erfgenamen toekent. De aard van de aanspraak gelijkt die van artikel 205bis BelgBW, de kring van gerechtigden echter verschilt beduidend. In de Nederlandse literatuur is wel geopperd de onderhoudsclaim uit te breiden tot de groep van personen voor wie de erflater bij leven onderhoudsplichtig is (art. 1:392 e.v. NedBW). ${ }^{22}$

Ten tweede dringt de gelijkenis zich op met het Engelse erfrecht, waarin geen reserve of legitieme portie bestaat, maar wel een aan de rechterlijke discretie overgelaten 'family provision'. ${ }^{23}$ De Engelse rechter kan een verzoek gegrond op de Inheritance Act 1975 toekennen 'on the ground that the disposition of the deceased's estate effected by his will or the law relating to intestacy, or the combination of his will and that law, is not such as to make reasonable financial provision for the applicant'. ${ }^{24}$ De erflater die zijn naaste redelijk verzorgd achterlaat, ontneemt laatstgenoemde de mogelijkheid om op deze grond tegen de uiterste wil te ageren. Bij de beoordeling of een reasonable financial provision is gemaakt, heeft de rechter grote vrijheid in het wegen van alle

(art. 4:32 NedBW). Door deze laatste toevoeging verliest het artikel elke praktische hanteerbaarheid, aangezien de termijn de facto wordt verlengd tot het moment waarop men is uitgeprocedeerd over de vraag aan wie de vertraging in de echtscheidingsprocedure te wijten is. Aldus R.L. Albers-Dingemans e.a., Eindverslag Commissie Erfrecht KNB inzake Boek 4 BW (I), WPNR 2010/6866, p. 879-890.

22. J.G. Klaassen, J. Eggens, E.A.A. Luijten \& W.R. Meijer, Huwelijksgoederen- en erfrecht. Tweede gedeelte: Erfrecht, Deventer: Kluwer 2008, nr. 661, W.D. Kolkman, Schulden der nalatenschap (diss. Groningen), Deventer: Kluwer 2006, par. 1.7.5, Albers-Dingemans e.a., Eindverslag Commissie Erfrecht KNB inzake Boek 4 BW (I), p. 879-890.

23. Zie de bijdrage van Beuker in dit themanummer.

24. S. 1 (1) Inheritance Act 1975. omstandigheden van het geval. ${ }^{25}$ In de conclusie van deze bijdrage kom ik hierop terug.

\section{Inbreng}

Inbreng van giften herstelt bij de verdeling van de nalatenschap de gelijkheid tussen de erfgenamen. Bij het leerstuk van de inbreng rijst de vraag in hoeverre de wet tot deze gelijkheid moet leiden. Oud en nieuw Belgisch recht geven een verschillend antwoord op deze vraag; het Nederlandse recht komt met nog weer een andere oplossing.

Het oude Belgische erfrecht ging uit van dit herstel van gelijkheid door het 'vermoeden van inbreng', zowel voor afstammelingen als voor anderen: giften zijn in beginsel een voorschot op het erfdeel. De waardering van de in te brengen giften vormde een complicerende factor: de inbreng van onroerende goederen geschiedde in natura volgens de waarde bij de verdeling, terwijl de inbreng van roerende goederen gebeurde door mindere ontvangst (dus in waarde) volgens de waarde op het ogenblik van de schenking. ${ }^{26}$ De problemen laten zich raden: wanneer een ouder aan een kind een registergoed schenkt en aan een ander kind een som geld, kan gemakkelijk scheefgroei ontstaan. ${ }^{27}$

Het nieuwe Belgische recht behoudt het vermoeden van inbreng slechts voor de giften aan afstammelingen. Voor giften aan anderen bestaat in beginsel geen inbrengplicht (een vermoeden van vrijstelling derhalve); deze kan wel worden opgelegd. Daarnaast vervalt de gedifferentieerde waarderingsmaatstaf. Voor de inbreng geldt nu de intrinsieke waarde van het goed op de dag van de schenking, met indexering (art. $858 \S 3$ lid 1 BelgBW). Zie daarover hierboven.

De huidige Belgische inbrengregeling is vergelijkbaar met die van het Nederlandse recht van voor 2003. In Nederland onderscheidde het oude erfrecht tussen erfgenamen in nederdalende linie en andere erfgenamen. Eerstgenoemden moesten volgens artikel 1132 NedBW oud 'alle schenkingen onder de levenden, welke zij van de erflater hebben genoten, inbrengen (...), ten ware de giften met uitdrukkelijke vrijstelling van inbreng zijn gedaan, of de begiftigden bij eene authentieke akte, of bij uitersten wil, van de verpligting tot inbreng zijn ontheven'. De andere erfgenamen waren slechts tot inbreng gehouden wanneer de schenker of testateur dit uitdrukkelijk had 'bevolen of bedongen'.

De Nederlandse regeling is in 2003 grondig op de schop gegaan. Erfgenamen zijn thans verplicht ten behoeve van hun mede-erfgenamen de waarde van de hun door de erflater gedane schenkingen in te brengen, voor zover de erflater dit, hetzij bij de schenking, hetzij bij uiterste wilsbeschikking, heeft voorgeschreven (art. 4:229 lid 1

25. S. 3 (1) Inheritance Act 1975

26. Zie MvT, Parl. St. Kamer, 54 2281/001, p. 3.

27. Zie voor een cijfervoorbeeld MvT, Parl. St. Kamer, 54 2281/001, p. 18. 
NedBW). In alle gevallen een vermoeden van vrijstelling derhalve. Dit sluit naadloos aan bij de notariële praktijk, waar het vrijstellen van inbreng gemeengoed was (en is). ${ }^{28}$ Deze wijziging heeft het belang van de rechtsfiguur inbreng in Nederland nog verder doen afnemen. Een bevoordeling bij leven geldt in beginsel als vooruitmaking.

Toch liggen de beide regelingen iets minder ver uit elkaar dan hun tegenovergestelde uitgangspunten doen vermoeden. Het verschil tussen Nederland en België is bij de schenkingen (bevoordelingen onder de levenden) aan afstammelingen groot, maar bij de testamentaire bevoordelingen minimaal. Als gezegd valt onder de Belgische term 'gift' zowel de Nederlandse gift (dat wil zeggen inter vivos) als het Nederlandse legaat. Het Nederlandse recht spreekt niet van 'inbreng van legaten', maar kent wel als hoofdregel dat een legaat, tenzij het aan één of meer bepaalde erfgenamen of legatarissen is opgelegd, ten laste van de gezamenlijke erfgenamen komt. De belaste erfgenamen zijn ieder voor een deel, evenredig aan het erfdeel, verbonden voor het legaat (art. 4:117 lid 2 en 3 NedBW). ${ }^{29}$ Het resultaat is evenwel niet hetzelfde als in België: het Nederlandse legaat wordt in beginsel door alle erven naar rato gedragen, het Belgische komt - onder de noemer 'inbreng' - ten volle voor de kiezen van de prelegataris.

\section{Erfovereenkomsten}

\subsection{Algemeen}

In mijn optiek zijn de verschillen tussen België en Nederland het grootst bij het contracteren over nietopengevallen nalatenschappen. Grofweg zijn erfovereenkomsten in Nederland verboden, terwijl ze in België onder voorwaarden zijn toegestaan.

Het Nederlandse recht bepaalt dat nietig is de voor het openvallen van een nalatenschap verrichte rechtshandeling die de strekking heeft een persoon te belemmeren in zijn vrijheid om erfrechtelijke bevoegdheden uit te oefenen (art. 4:4 lid 1 NedBW). Daarnaast volgt uit artikel 4:4 lid 2 NedBW dat met dezelfde nietigheid worden getroffen overeenkomsten strekkende tot beschikking over nog niet opengevallen nalatenschappen in hun geheel of over een evenredig deel daarvan. Op deze starre regel laat de wet geen uitzonderingen toe, ongeacht of het om de eigen nalatenschap gaat dan wel die van een derde. Contracteren over bepaalde goederen uit een toekomstige nalatenschap is echter wel toegestaan, zoals door verblijvensbedingen. ${ }^{30}$ In de Nederlandse literatuur wordt wel gepleit voor aanpassing van artikel 4:4

28. W.D. Kolkman, Inbreng van giften in het nieuwe erfrecht, Tijdschrift Nieuw Erfrecht 2003, afl. 1, p. 6.

29. Zie W.D. Kolkman, Het legaat ten laste van een der erfgenamen, Tijdschrift Nieuw Erfrecht 2004, afl. 2, p. 29 en G.G.B. Boelens, Het legaat, de wisselwerking tussen civiel en fiscaal recht (diss. Leiden), Deventer: Wolters Kluwer 2015, p. 214 e.v.

30. Parl. Gesch. Boek 4 BW Inv., p. 1179.
NedBW om erfovereenkomsten op enige schaal toe te staan. ${ }^{31}$

In diverse landen in Europa is dat reeds realiteit. ${ }^{32} \mathrm{Zo}$ ook in België. In de nieuwe titel IIbis (Erfovereenkomsten) zijn de mogelijkheden nauwkeurig omlijnd. Nagenoeg geheel verboden blijven de overeenkomsten over de nalatenschap van een derde (art. 1100/1 $\$ 1$ BelgBW). Met betrekking tot de eigen nalatenschap bestaat de nodige ruimte, maar ook in België moet het contract in de meeste gevallen specifieke goederen betreffen en niet de algemeenheid van goederen, noch een evenredig deel daarvan. ${ }^{33}$ Onderscheid wordt gemaakt tussen de specifieke ('punctuele') en de algemene ('globale') erfovereenkomst.

\subsection{Punctuele en globale erfovereenkomsten}

Al voor 1 september 2018 kende het Belgische recht enkele punctuele erfovereenkomsten. Zo waren en blijven toegestaan de contractuele erfstellingen in huwelijkse voorwaarden (art. 1082 BelgBW). Opvallend is dat deze mogelijkheid in Nederland met de invoering van het erfrecht in 2003 is geschrapt. Enerzijds hield dit verband met het geringe praktische belang van deze 'huwelijkse giften' (erfstellingen en legaten), anderzijds met de complicerende werking die van handhaving zou uitgaan op het erfrecht, aldus de parlementaire toelichting. ${ }^{34}$

Het Belgische recht ontwikkelt zich hier in een tegengestelde richting. De nieuwe wet voegt aan de bestaande punctuele overeenkomsten onder meer toe de overeenkomst over de inbreng bij 'generation skipping' (art. 845 $\S 2$ BelgBW), over de waarde van een gift (art. 858 § 5 BelgBW) en over de afstand van inkorting op een gift (art. 918 BelgBW). ${ }^{35}$

Opvallender nog dan de uitbreiding van de punctuele overeenkomsten is de introductie van de globale erfovereenkomst. Zij kan worden gesloten door één ouder of door de beide ouders, altijd tezamen met al hun vermoedelijke erfgenamen in rechte nederdalende lijn. ${ }^{36} \mathrm{De}$ kern van het familiepact staat in artikel $1100 / 7$ § 1 BelgBW:

31. Schols brak hiervoor een lans in zijn proefschrift uit 2005, F.W.J.M. Schols, Quasi-erfrecht met bindende elementen (diss. Nijmegen), Deventer: Kluwer 2005. Zie ook J.H. Lieber, De erfovereenkomst om ruzie te voorkomen, FJR 2017, afl. 2, p. 55.

32. Duitsland bijvoorbeeld kent het gemeenschappelijk testament, het Erbvertrag en het Erbverzicht. Zie A. Dutta, Grenzen der Vertragsfreiheit im Pflichtteilsrecht, Archiv für die civilistische Praxis 2009, 209 H6, p. 760-806. Italië kent sinds 2006 de patto di famiglia, de erfovereenkomst met betrekking tot het bedrijf van de erflater in spe, art. 768bis e.v. Codice civile. Dit familiecontract beoogt een gladde bedrijfsopvolging, met instemming van (en later bestand tegen) alle legitimarissen. Zie Braun, Testamentary freedom and its restrictions in French and Italian law, p. 76.

33. A.L. Verbeke, Nieuw Belgisch erfrecht, Rechtskundig Weekblad 2017-18, nr. 28, p. 1097.

34. Kamerstukken II 1999/2000, 27245, 3, p. 3 (MvT) en Schols, Quasierfrecht met bindende elementen, p. 161.

35. Deze laatste werd onlangs ook in Frankrijk ingevoerd: sinds 2007 bestaat daar de 'RAAR' (la renonciation anticipée à l'action en réduction). Zie art. 929 e.v. Cc.

36. Vergelijk de eisen die het Nederlandse erfrecht aan de ouderlijke boedelverdeling (art. 1167 NedBW oud) stelde: alle kinderen moesten daarin betrokken worden, de echtgenoot was facultatief. 
'Deze overeenkomst stelt het bestaan vast van een evenwicht tussen deze vermoedelijke erfgenamen, rekening houdende met onder meer de schenkingen die de ouder hen respectievelijk heeft toegestaan vóór de overeenkomst, als voorschot op erfdeel of bij vooruitmaking, met de schenkingen toegekend in de overeenkomst zelf en, in voorkomend geval, met de situatie van elk van de vermoedelijke erfgenamen.'

De crux van de globale erfovereenkomst is het vaststellen van een evenwicht tussen de kinderen; dit is iets anders dan volstrekte gelijkheid. Om dit evenwicht te bereiken is transparantie vereist. Het slot van artikel $1100 / 7$ \& 1 BelgBW bepaalt daarom dat de overeenkomst het geheel van de huidige en vroegere schenkingen en voordelen ${ }^{37}$ waarmee rekening wordt gehouden, vermeldt en daarnaast hoe de partijen dit evenwicht hebben opgevat en aanvaard. Het gevolg van de overeenkomst is onder meer het verlies van vorderingen tot inkorting en inbreng (art. 1100/7 §6 BelgBW). Aldus creëert zij een status quo die zekerheid biedt.

Het opstellen van de familieovereenkomst lijkt mij geen eenvoudige kost, en zeker geen 'modellenwerk'. Verbeke wijst er terecht op dat niet zozeer een juridisch-technische aanpak wordt gevergd, als wel een zorgvuldige en doordachte facilitering van gesprekken tussen de familieleden, waarbij men alle onderliggende belangen en bekommernissen van alle betrokkenen, kinderen én ouders, zorgvuldig beluistert en respecteert. ${ }^{38}$ Bekwaamheid op het gebied van mediation zal de opsteller goed van pas komen.

\subsection{Vormvoorschriften}

De vormvoorschriften voor de erfovereenkomsten zijn indrukwekkend. Om te beginnen geldt de eis van notariele akte (art. 1100/5 § 1 BelgBW). ${ }^{39}$ Voorts geldt dat het ontwerp van de overeenkomst door de instrumenterende notaris aan elke partij wordt meegedeeld. Deze notaris legt tegelijk een vergadering vast waarop de inhoud van de overeenkomst en de gevolgen ervan aan alle partijen worden toegelicht. Bij die gelegenheid informeert hij elke partij over de mogelijkheid een aparte raadsman te kiezen of een individueel onderhoud met hem te hebben. Ter vergadering wijst hij nogmaals op die mogelijkheid. De vergadering kan pas worden gehouden na verloop van een termijn van vijftien dagen, die ingaat op

37. Denk hierbij aan de voordelen waarvan zij hebben kunnen genieten 'vanwege hun ouders' - zoals de kosten om in het buitenland te studeren of de mogelijkheid om gratis in een onroerend goed van de ouders te wonen - en die, op voorwaarde dat iedereen akkoord gaat, gelijkgesteld kunnen worden aan schenkingen in het kader van de overeenkomst, teneinde het evenwicht te bereiken. Vergelijk MvT, Parl. St. Kamer, 54 2281/001, p. 25.

38. Verbeke, Nieuw Belgisch erfrecht, p. 1099.

39. Voor de hierboven genoemde Franse RAAR geldt als vormvereiste dat zij wordt opgenomen in een specifiek daarvoor opgestelde authentieke akte, verleden door twee notarissen. Zie art. $930 \mathrm{Cc}$. De interventie van de tweede notaris werd nodig geacht om te verzekeren dat degene die afstand doet hiertoe in vrijheid en met kennis van zaken overgaat. Vergelijk F. Sauvage, La renonciation anticipée à l'action en réduction, AJ Famille 2006, p. 355. de dag waarop het ontwerp is meegedeeld. De overeenkomst kan niet worden ondertekend vóór het verstrijken van een termijn van één maand, die ingaat vanaf de dag waarop die vergadering heeft plaatsgevonden. Elke partij kan een beroep doen op een andere notaris, die haar zal bijstaan bij het verlijden van de akte. De datum van verzending van het ontwerp van de overeenkomst en de datum waarop de vergadering heeft plaatsgevonden, worden in de overeenkomst vermeld. Zie voor dit alles artikel 1100/5 § 2 BelgBW.

Opmerkelijk vind ik de termijnen van respectievelijk vijftien dagen en een maand. Van deze termijnen kan niet worden afgeweken, zelfs niet met instemming van partijen (art. 1100/5 $§ 2$ BelgBW). Het meest vlotte traject - met louter coöperatieve en eensgezinde familieleden - zal dus altijd nog ruim anderhalve maand in beslag nemen. Gelet op de grote belangen valt dit dwingende tijdschema wel te billijken. Overijling krijgt op deze manier geen kans. Anderzijds maakt het de erfovereenkomst ongeschikt voor estate planning in extremis.

Voor het niet in acht nemen van de voorschriften toont de Belgische wet geen coulance: elke erfovereenkomst die niet door de wet is toegelaten of waarbij de strenge vormvereisten zijn miskend, is absoluut nietig (art. 1100/3 BelgBW). Registratie van de erfovereenkomst in het Belgische CTR is weliswaar voorgeschreven (art. 1100/6 BelgBW), maar geldt niet als constitutief vereiste voor de geldigheid, evenmin voor de tegenwerpbaarheid jegens derden. ${ }^{40}$

\section{Conclusie}

In het bovenstaande kwamen de drie meest in het oog springende wijzigingen van de Belgische Erfwet 2017 aan bod: de aard en omvang van de erfrechtelijke reserve, de regels der inbreng en de uitbreiding van de erfovereenkomsten. In mijn optiek is de Belgische wetgever er hiermee in geslaagd het erfrecht bij de tijd te brengen, alhoewel er uiteraard altijd wat te wensen overblijft.

De stap van de oude 'napoleontische' reserve naar de nieuwe geldaanspraak vind ik een logische, maar had niet nog een stap verder moeten worden genomen? Interessant is de nieuwe Belgische ascendentenreserve: een onderhoudsaanspraak (in geld). De Nederlandse verzorgingsvruchtgebruiken voor de langstlevende zijn dat eveneens. Mijns inziens is deze 'aanpak op maat' zowel in België als in Nederland over de gehele reservataire linie te verkiezen boven de forfaitaire ('blinde') legitieme of reserve. ${ }^{41}$

40. MvT, Parl. St. Kamer, 54 2281/001, p. 133.

41. Voor een soortgelijk standpunt inzake België, zie A.L. Verbeke, Hervorming van Belgisch erfrecht, TEP 2011, afl. 1-2, p. 11 en W.D. Kolkman, Dwingend erfrecht in Europa. Pleidooi voor afschaffing van de legitieme portie, in: R.J.C. Flach, G.T. de Jong, R. Koolhoven \& F.J. Vonck (red.), 
Op het gebied van de inbreng vraag ik mij af of het 'vermoeden van inbreng' (dat behouden blijft bij de giften aan afstammelingen) niet plaats had moeten maken voor het vermoeden van vrijstelling, zoals dit in Nederland is gebeurd in 2003. Eens gegeven blijft gegeven; no strings attached.

Ten aanzien van de erfovereenkomsten juich ik de Belgische ontwikkeling van harte toe. Het doel van deze contracten springt in het oog: de justitiabele regelt zijn toekomstige nalatenschap in alle transparantie en poogt te voorkomen dat na zijn overlijden conflicten ontstaan tussen de erven. ${ }^{42}$ Deze grotere autonomie tijdens leven biedt de estate planner een prachtig instrument. Vanzelfsprekend bestaan er ook schaduwzijden (denk onder meer aan de binnen de familie uitgeoefende druk om te tekenen), maar met degelijke waarborgen kunnen deze tot een minimum beperkt blijven. 